Revista Destaques Acadêmicos, Lajeado, v. 10, n. 4, 2018. ISSN 2176-3070

DOI: http://dx.doi.org/10.22410/issn.2176-3070.v10i4a2018.1929

http://www.univates.br/revistas

\title{
PROCESSOS DE VERMICOMPOSTAGEM CONTENDO HIDROCARBONETOS POLICÍCLICOS AROMÁTICOS COMO CONTAMINANTES: UMA REVISÃO
}

\author{
Alana Uebel ${ }^{1}$, Maira Post Muller ${ }^{2}$, Maitê Nieland Lampert ${ }^{3}$, \\ Maria Cristina Dallazen ${ }^{4}$, Rafaela Ziem ${ }^{5}$, Gabriela Vetorello ${ }^{6}$, \\ Daniel Kuhn ${ }^{7}$, Lucélia Hoehne ${ }^{8}$
}

\begin{abstract}
Resumo: Vermicompostagem é o processo de transformar os resíduos orgânicos em compostos de qualidade, em pouco tempo, comouso de minhocas e dos microorganismos existentes no meio. Os resíduos orgânicos podem ser oriundos de diferentes fontes, até mesmo de compostos tóxicos e difíceis de serem degradados. Assim, esse artigo tem o objetivo de evidenciar trabalhos que usaram solos contendo os hidrocarbonetos policíclicos aromáticos (HPAs) no processo da vermicompostagem. Desse modo, foi possível verificar alguns métodos de extração de HPAs de forma adequada, bem como usar o processo da vermicompostagem para degradar esses compostos.
\end{abstract}

Palavras-chave: Vermicompostagem. Minhocas. HPAs. Húmus.

\section{INTRODUÇÃO}

Os resíduos orgânicos constituem hoje, um dos principais problemas enfrentados pela humanidade. Com o crescimento populacional há a geração de mais resíduos e consequentemente, aumentam os impactos ambientais.

1 Graduanda em Engenharia Química pela Univates.

2 Graduanda em Engenharia Química pela Univates.

3 Graduanda em Engenharia de Controle e Automoção pela Univates.

4 Graduanda em Química Industrial pela Univates.

5 Graduanda em Engenharia Química pela Univates.

6 Graduanda em Química Industrial pela Univates.

7 Mestrando pelo Programa de Pós-Graduação em Biotecnologia pela Univates.

8 Programa de Pós-Graduação em Biotecnologia pela Univates. 
Tendo em vista essa problemática e pensando numa maneira sustentável e alternativa da utilização destes compostos orgânicos, surgem processos de transformar esses, em compostos de grande qualidade em pouco tempo, chamados de compostagem e de vermicompostagem (DORES-SILVA; LADGRAF; REZENDE, 2013).

A compostagem é a degradação da matéria orgânica pelos microrganismos que já existem no meio dos resíduos orgânicos e do solo. Quando feita em pequena escala, se torna mais fácil, pois até dois terços do lixo doméstico diário pode ser reciclado sem nenhuma dificuldade, de forma higiênica e econômica. Podendo assim minimizar o impacto ambiental que a sociedade produz na forma de fertilizante.

De acordo com Grangeiro et al., (2006), a compostagem se caracteriza como um processo biológico aeróbico de tratamento e estabilização de resíduos orgânicos gerando um composto orgânico rico em nutrientes. Nesse processo, a matéria orgânica se decompõe principalmente através da ação de microrganismos e enzimas, tendo como resultado a fragmentação gradual e oxidação dos detritos.

A compostagem transforma materiais orgânicos de maneira biológica em fertilizantes orgânicos utilizáveis na agricultura. Milhões de microrganismos são envolvidos no processo, já presentes no próprio material ou por meio de um pré-inóculo, utilizando matéria orgânica in natura como fonte de energia, nutrientes minerais e carbono, promovendo a mineralização de parte do material e a humificação de outra parte. (DORES-SILVA; LADGRAF; REZENDE, 2013)

A composteira é um depósito para o processamento do material orgânico. É nela que ocorre a compostagem, ou seja, a transformação desse lixo orgânico em adubo. Seu formato e tamanho pode ser diferenciado dependendo do volume de matéria orgânica que é produzida e do espaço livre em que há disponível. A compostagem é uma ótima iniciativa, tendo em vista que são adaptáveis a tamanhos e preços (WANGEN; FREITAS, 2010).

Os fatores responsáveis pela eficiência do processo de compostagem estão diretamente relacionados às condições favoráveis para que os microrganismos aeróbicos possam se multiplicar e atuar na decomposição da matéria orgânica (KIEHL, 1998).

Já a vermicompostagem, é o processo de compostagem com o auxílio das minhocas para degradar mais rápido os compostos (Loureiro et al., 2007). Assim, a decomposição da matéria orgânica pode ser feita usando diferentes resíduos, até mesmo os mais difíceis de serem degradados.

A vermicompostagem é a decomposição dos resíduos orgânicos realizada pelos microrganismos e por minhocas, sendo uma opção simples de reciclar os resíduos alimentares e de se obter húmus com propriedades excelentes para fertilização do solo, sem a necessidade de serem usados fertilizantes sintéticos, preservando o meio ambiente. Utilizando altas densidades e estimulando a 
ação de bactérias e fungos aeróbios, as minhocas digerem, oxidam, mineralizam e humificam os materiais que passam por seu trato intestinal, gerando o vermicomposto, rico em nutrientes, fauna microbiana e reguladores de crescimento vegetal. Após esses compostos passarem pelo trato digestivo das minhocas, são biotransformados em húmus, um composto rico em nitrogênio, cálcio, fósforo, magnésio e potássio, que podem ser utilizados como fertilizantes (VALDERRAMA et al., 2011; MARCONDES, 1994). O húmus não apresenta acidez elevada e as vermicomposteiras podem ser feitas em apartamentos e casas necessitando de pouco espaço (KIEHL, 1998).

O produto final da vermicompostagem, possui altos teores de nitrogênio, potássio e fósforo, que são nutrientes indispensáveis absorvidos pelas plantas. Eles constituem os macronutrientes (DORES-SILVA; LADGRAF; REZENDE, 2013). Sem a presença destes, a planta apresenta carência de nutrientes acarretando má formação e crescimento reduzido, queda das folhas e em casos de muita escassez até a perda da planta. Nutrientes em excesso podem causar crescimento vegetal acelerado, diminuição da resistência a doenças e o amarelecimento das folhas (GOTO; GUIMARÃES; ECHER, 2001).

Os resíduos mais comuns para o processo de vermicompostagem são originários de estações de tratamentos de efluentes (VERAS; POVINELLI, 2004), resíduos hospitalares e domiciliares (LOUREIRO et al., 2007), vegetais em decomposição. No entanto, o uso da vermicompostagem pode ser aplicado para outros tipos de solos contendo resíduos orgânicos um tanto quanto tóxicos, como, por exemplo, solos contaminados com metais pesados, como por exemplo Cr em cebolinhas (MARTINI et al., 2015) e $\mathrm{Pb}$, Cd e Cr em plantio de aveia preta (HOEHNE et. al., 2016). Além disso, a vermicompostagem pode ser usada em solos contendo contaminação por hidrocarbonetos policíclicos aromáticos (HPAs).

Os HPAs (Figura 1) são compostos que possuem 2 ou mais anéis aromáticos condensados. Estas substâncias, bem como seus derivados nitrados e oxigenados, têm ampla distribuição e são encontrados como constituintes de misturas complexas em todos os compartimentos ambientais (HICKMAN; REID, 2008). Os HPAs são declarados poluentes orgânicos prioritários segundo estudos ambientais, e alguns dos contaminantes retratados como pioneiros de ações mutagênicas e tumorais em sistemas biológicos. 
Figura 1: Estruturas químicas de alguns HPAs.

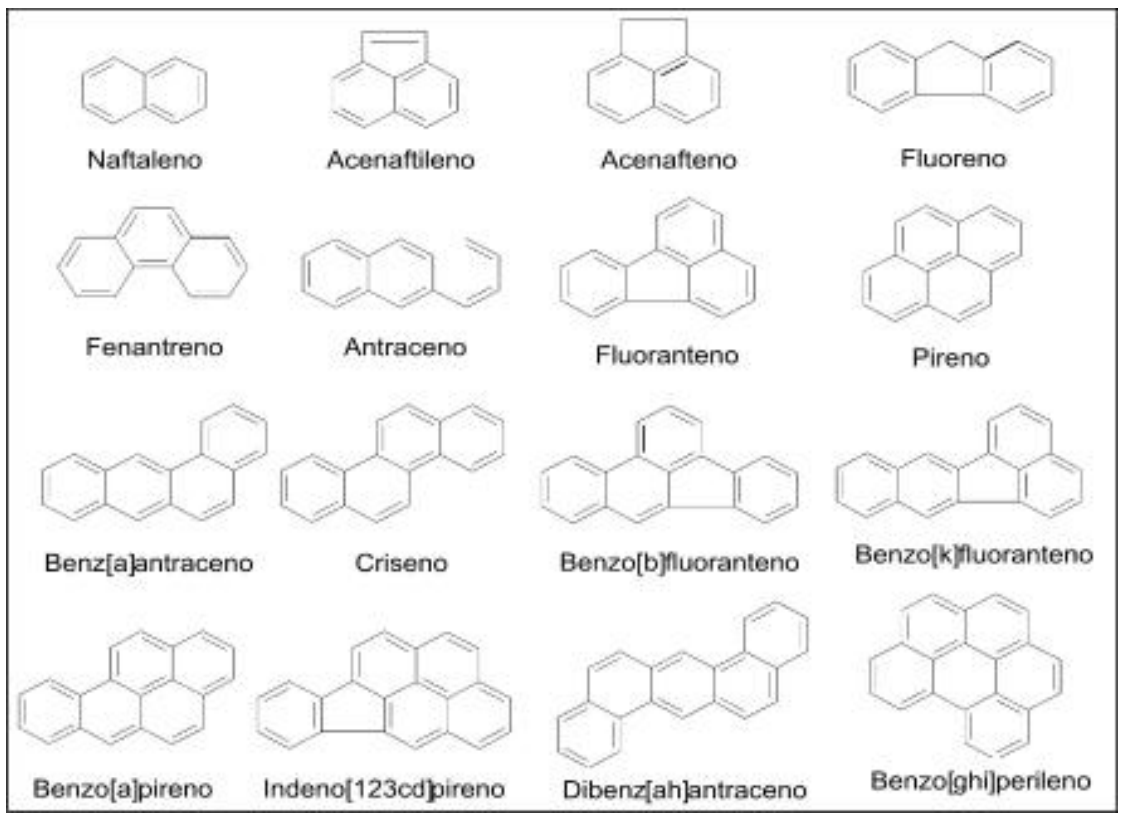

As principais fontes de HPAs para o meio ambiente são incêndios em florestas e em campos, assim como a queima de combustível fóssil. Todavia, as emissões ligadas aos processos industriais de aço e alumínio, da exaustão de incineradores de rejeito e resíduos de sólidos industriais, são as mais abundantes. Outras atividades que aumentam os níveis de HPAs no meio ambiente, incluem atividades petroquímicas como o processo de refino na produção de petróleo, e também os acidentes de derramamento direto de produtos e subsequentes em rios, lagos ou oceanos. (PAGE et al., 1999; YUNKER et al., 2002; SISINNO et al., 2003).

Foram realizados trabalhos relacionando a atividade carcinogênica dos diferentes HPAs com suas estruturas químicas. Eles sofrem ativação metabólica preliminar para se tornarem capaz de reagir com o Ácido Desoxirribonucléico (DNA) e as outras macromoléculas. Os resultados mostram que os efeitos dos diferentes compostos são variáveis, a capacidade carcinogênica e mutagênica dos diferentes HPAs é expressivo para aqueles que possuem mais de 4 anéis aromáticos e maior para aqueles que tem mais de 5 ou 6 anéis (KANALY, HARAYAMA, 2000; BAMFORTH; SINGLETON, 2005). O poder carcinogênico/ mutagênico no organismo varia de uma espécie para outra, dependendo da via de contaminação, via respiratória ou então via dérmica. Pesquisas relatam que $90 \%$ da carga ambiental de HPAs está presente nos solos e há a necessidade de remediação dos locais contaminados devido aos riscos que esses compostos representam para os receptores. Uma técnica utilizada para a redução dos altos níveis de contaminação é transportar e acumular os solos já contaminados, 
como o de aterros sanitários, porém essa técnica é pouco segura, uma vez que é uma ameaça transferida para gerações futuras (KANALY; HARAYAJA, 2000; BAMFORTH; SINGLETON, 2005).

Um solo é considerado como não poluído se o teor padrão de HPA for $<0,2-0,6 \mathrm{mg} \mathrm{kg}^{-1}$ de HPAs. Se o teor total de HPAs estiver entre 0,6 e 1, 1-5, $5-10$ e> $10 \mathrm{mg} \mathrm{kg}^{-1}$, o solo é considerado como ligeiramente poluído, poluído, fortemente poluído e muito poluído, respectivamente. Dependendo da fonte de contaminação, os solos podem conter concentrações de HPA variando entre 0.001 e $300.000 \mathrm{mg} \mathrm{kg}^{-1}$ de PAH totais (KANALY; HARAYAMA, 2000; BAMFORTH; SINGLETON, 2005).

Como pode ser visto, os HPAs tem efeitos no solo e é uma preocupação dar um tratamento adequado para esses compostos. Considerando isso, a busca de uma alternativa relativamente barata, pode ser no processo de vermicompostagem.

Como há poucos relatos na literatura, o objetivo deste artigo foi fazer uma busca bibliográfica para mostrar trabalhos que usaram a vermicompostagem em solos contendo os hidrocarbonetos policíclicos aromáticos.

\section{METODOLOGIA}

No período de novembro de 2017 a fevereiro de 2018 foi realizada uma revisão bibliográfica nas publicações indexadas nas bases de dados SciELO, Pubmed e LILACS, no intuito de verificar os artigos publicados em que se utilizou HPAs em processos de vermicompostagem para avaliar os efeitos que podem ocorrer tanto no solo quanto nas minhocas.

As informações contidas nos artigos selecionados por esta revisão foram resumidas de forma independente nos seguintes tópicos: autor, desenho do estudo, objetivo, método, resultados e conclusão.

Contreras-Ramos, Álvarez-Bernal e Dendooven (2007) avaliaram a dinâmica do nitrogênio usando vermicomposto em solos contaminados com HPA. Para isso, fenantreno $\left(\mathrm{C}_{14} \mathrm{H}_{10}\right)$, antraceno $\left(\mathrm{C}_{14} \mathrm{H}_{10}\right)$ e Benzo(a)pireno (BaP) foram avaliados em solos contendo minhocas. Para isso, foi usada a minhoca Eisenia fetida em biossólido (1800 g) obtido de uma estação de tratamento de águas residuais em Lerma, estado do México, e misturado com $800 \mathrm{~g}$ de esterco de vaca e água. Os solos foram contaminados com $100 \mathrm{mg} \mathrm{kg}^{-1}$ de fenantreno, $500 \mathrm{e} \mathrm{mg} \mathrm{kg}^{-1}$ de antraceno e $50 \mathrm{mg} \mathrm{kg}^{-1}$ de Benzo(a)pireno. Estas concentrações foram utilizadas por não serem tóxicas para Eisenia fetida Em um outro trabalho, as minhocas adultas foram incubadas nesse meio contendo HPAs por 3 meses. As análises foram feitas através da cromatografia a líquido de alta eficiência (CLAE). De acordo com os resultados, houve transformação do nitrogênio amoniacal em nitrato, deixando este elemento de forma mineralizada, sendo assim usado como fertilizante. Não houve estudos sobre bioacumulação de 
HPAs nos tecidos das minhocas (CONTRERAS-RAMOS; ÁLVAREZ-BERNAL; DENDOOVEN, 2008).

Cotta, Oliveira e Landgraf (2009) avaliaram a presença de HPAs em solo após a presença e minhocas Eisenia fetida. Os HPAs analisados foram: Naftaleno, Acenaftileno, Acenafteno, Fluoreno, Fenantreno, Antraceno, Fluoranteno, Pireno, Benzo[a]antraceno, Criseno, Benzo[e]pireno, Benzo[e]acefenantrileno, Benzo[k]Fluoranteno, Benzoa[a] pireno, Dibenzo[a, h]antraceno, Benzo[g, $\mathrm{h}$, i]perileno e Indeno[1,2,3cd] pireno. Como preparo da amostra, a extração por ultrassom foi escolhida por baixo custo operacional e fácil operação, além de minimizar o uso de solvente e não levar a perdas por evaporação. Os 17 HPAs foram bem separados e determinados por CLAE com detector UV-Vis e fluorescência usando uma coluna C-18 e misturas acetonitrilina-água como fase móvel. O tempo de corrida foi de $20 \mathrm{~min}$. A acetona foi o melhor solvente entre os três avaliados para a extração dos 17 HPAs em solo, seguida do metanol e da acetonitrila. Pode-se concluir que o desenvolvimento da técnica de extração dos 17 HPAs foi eficiente, mas o artigo não trouxe dados em relação à presença ou não desses compostos nos tecidos das minhocas, nem como o perfil do solo.

Contreras-Ramos, Álvarez-Bernal e Dendooven (2008), analisaram solo esterelizado e não esterelizado contaminados com fenantreno, antraceno, benzeno(a)pireno, com ou sem adição da minhoca Eisenia fetida. As concentrações de HPAs foram adicionadas no solo e monitoradas por 70 dias. Foram feitas extrações usando ultrassom e determinação por CLAE. A remoção dos HPAs em solo com minhocas foi de 91\% para o antraceno, 16\% para o benzeno(a)pireno e $99 \%$ para o fenantreno. Já em solo não esterelizado, a remoção foi de $42 \%$, 3\% e 95\%, respectivamente. Dessa forma, pode-se verificar que as minhocas possuíram um efeito nos HPAs, facilitando sua extração do solo.

Martinkosky, et al., (2017) avaliaram a redução de HPAs em solos contendo óleo bruto após a vermicompostagem. Neste estudo, a minhoca Eisenia fetida foi testada quanto à utilidade para melhorar a remediação do solo afetado pelo óleo. A sobrevivência de E. fetida em solo contaminado com dois óleos brutos distintos foi testada em um solo argiloso arenoso artificial, e a sobrevivência comparada àquela no solo sem óleo. O petróleo bruto com uma elevada fração de hidrocarbonetos leves foi mais tóxico para as minhocas do que o petróleo bruto com uma elevada proporção de hidrocarbonetos poliaromáticos e alifáticos pesados. $\mathrm{O}$ óleo bruto mais pesado foi adicionado ao solo para criar um solo contendo petróleo bruto de $30.000 \mathrm{mg} / \mathrm{kg}$ e a degradação na presença de minhocas e rações adicionadas, alimentação sozinha ou sem adições foi monitorizada ao longo do tempo. As análises foram feitas por cromatografia. Como resultados, a taxa de degradação de HPA total para os tratamentos contendo minhoca foi $\sim 90 \mathrm{mg} /$ dia abrandando em 200 dias. Durante estes experimentos, os solos foram moderadamente tóxicos durante os primeiros três meses, no entanto, as minhocas sobreviveram. Este estudo 
demonstrou que as minhocas aceleram a biorremediação do petróleo em solos, incluindo a degradação das frações poliaromáticas mais pesadas.

Johnson et al., (2002), usou a minhoca Aporrectodea longa para observar os impactos da biodisponibilidade de HPAs no solo. Dois HPAs (pireno e benz [a] antraceno) foram colocados em solo esterilizado e envelhecido. As minhocas foram adicionadas primeiramente no solo esterilizado e tiveram um período de 28 dias para se acostumarem ao ambiente. Após, os animais foram incubados nos solos contendo HPA, e foram monitorados aos 0, 30, 60 e 240 dias de incubação. Após a exposição, mediram-se as concentrações desses compostos nos tecidos das minhocas empregando uma técnica de extração sequencial com dois solventes de diferentes polaridades e a deteminação foi por cromatografia líquida de alta eficiência. Como resultados, a biodisponibilidade dos HPAs diminuiu com o aumento do tempo de contato com o solo. No entanto, pireno e benz [a] antraceno foram encontrados nos tecidos das minhocas. As concentrações nos tecidos das minhocas ao final de 240 dias foram de 10 $\mu \mathrm{g} / \mathrm{g}$ de pireno e de $4000 \mu \mathrm{g} / \mathrm{g}$ de benz [a] antraceno. Desse modo, espécies de minhocas podem ser importantes na determinação da bioacumulação de PAHs associadas ao solo. No entanto, observou uma acumulação nos tecidos, que, podem ser prejudiciais, podendo interferir em sua reprodução e ou sobrevivência. Cabe salientar que, o nicho ecológico ocupado pelas espécies experimentais pode influenciar, assim como o comportamento alimentar e, consequentemente, o grau de acumulação dos HPAs.

Gomes-Eyles, Collins e Hodson (2009) avaliaram se as proporções relativas de HPAs diferem entre bioensaios de acumulação e métodos químicos para prever a biodisponibilidade nos solos contaminados. Foram analisados métodos de extração dos HPAs no solo usando minhocas (Eisenia fetida) e raízes de centeio (Lolium multiflorum). O solo contaminado com HPAs foi envelhecido durante seis meses, contendo as minhocas e submetido às extrações de butanol, ciclodextrina e acetona-hexano, bem como uma extração para determinar as concentrações totais de HPAs em vários tempos. A determinação dos compostos foi feita com o uso de um cromatógrafo liquido de alta eficiência (HPLC). Como resultados, usando as extrações de butanol foi possível avaliar a acumulação de HPAs nas minhocas e usando ciclodextrina, butanol e acetonahexano foi possível extrair os compostos em raízes de centeio. Como resultados preliminares do trabalho, foi possível avaliar que houve bioacumulação no solo, sendo a maior proporção dos HPAs mais pesados (4-anéis). Testes mais precisos ainda devem ser feitos para verificar realmente quais os efeitos dos HPAs no solo e na microbiota. Os resultados de HPAs nas minhocas não foi divulgado neste trabalho.

Parrish et. al.,(2005) avaliaram a acumulação de HPAs em diferentes espécies de plantas e de minhocas. O solo foi coletado de uma fábrica de gás manufaturado que estava contaminado com 12 dos $16 \mathrm{HPAs}$ prioritários da Agência de Proteção Ambiental dos Estados Unidos (EPA). O solo já tinha 
sido determinado anteriormente por Yang et al.; (2001) e tinha um teor de carbono orgânico de 3,5\% e um pH de 6,0-6,1. Foram feitos 4 testes em 4 ciclos crescimento dos vegetais: um controle sem vegetação e três espécies de plantas diferentes. Foi plantado pepino, abrobrinha e abóbora de verão. As espécies de minhocas utilizadas foram E. fetida e L. terrestres. Estas foram adicionadas no solo contendo os vegetais. As análises foram feitas por CLAE, usando extração com solventes. Como resultados, durante o primeiro período de crescimento, abobrinha continha quantidades significativamente maiores de HPAs do que o pepino e a abóbora. Durante o primeiro ciclo de crescimento, as plantas de abobrinha absorveram até 5,47 vezes mais HPA total do que as outras plantas, incluindo até três ordens de magnitude de níveis maiores de seis HPAs. Ao longo dos ciclos de crescimento a acumulação de HPAs de abobrinha diminuiu $85 \%$, enquanto a absorção dos contaminantes pelo pepino permaneceu relativamente constante. Em todos os quatro ciclos de crescimento, a remoção de HPAs por abobrinha foi ainda o dobro da de outras espécies. As duas espécies de minhocas acumularam quantidades significativamente diferentes de HPAs a partir do solo: Eisenia foetida e Lumbricus terrestres continham 0,204 e $0,084 \mu \mathrm{g} / \mathrm{g}$ de HPA total.

\section{CONSIDERAÇÕES FINAIS}

De acordo com os relatos dos artigos usados nessa revisão, pode-se perceber que há poucas pesquisas que descrevem a determinação dos HPAs de solos após vermicompostagem. Foi possível verificar que há a necessidade de avaliar vários processos de extração para a determinação destes compostos. Usando a vermicompostagem, foi possível facilitar a extração dos HPAs, no entanto, poucos relataram sobre a bioacumulação destes nas minhocas e seus efeitos adversos. Assim, pode-se concluir que a presença de HPAs em solos que serão submetidos a um processo de vermicompostagem, merecem mais estudos sobre a sua toxicidade no solo e na biota.

\section{REFERÊNCIAS}

BAMFORTH, Selin M..; SINGLETON, Ian. Bioremediation of polycyclic aromatic hydrocarbons: current knowledge and future directions. Journal of Chemical Technology and Biotechnology, Sussex, v. 80, n. 7, p. 723-736, 2005.

CONTRERAS-RAMOS, Silvia M.; ÁLVARES-BERNAL, Dioselina; DENDOOVEN, Luc. Dynamics of nitrogen in a PAHs contaminated soil amended with biosolid or vermicompost in the presence of earthworms, Chemosphere, 67, Vol. 10, pg. 2072 $-2081,2007$.

CONTRERAS-RAMOS, Silvia M.; ÁLVARES-BERNAL, Dioselina; DENDOOVEN, Luc. Removal of polycyclic aromatic hydrocarbons from soil amended with biosolid 
or vermicompost in the presence of earthworms (Eisenia fetida). Soil Biology \& Biochemistry, Vol. 40, pg. 1954 - 1959, 2008.

COTTA, Jussara A. O.; OLIVEIRA, Maria O.; LANDGRAF, Maria D. Avaliação de solventes de extração por ultrassom usando-se cromatografia líquida de alta eficiência para a determinação de hidrocarbonetos policíclicos aromáticos em solos contaminados. Química Nova, v. 32, n. 8, p. 2026-2033, 2009.

DORES-SILVA, Paulo R.; LANDGRAF, Maria D.; REZENDE, Maria O. O. Processo de estabilização de resíduos orgânicos: vermicompostagem versus compostagem. Quimíca Nova, São Carlos, v. 36, n. 5, p. 640-645, 2013.

GOMES-EYLES, Jose. L.; COLLINS, Chris. D.; HODSON, Mark E. Relative proportions of polycyclic aromatic hydrocarbons differ between accumulation bioassays and chemical methods to predict bioavailability. Environmental Pollution, n. 158, p. 278-284, 2009.

GOTO, Rumy; GUIMARÃES, Vandeir F.; ECHER, Márcia M. Aspectos fisiológicos e nutricionais no crescimento e desenvolvimento de plantas hortícolas. Guaíba: Agropecuária, v. 2, p.241-268, 2001.

GRANGEIRO, Leilson C. et al. Acúmulo de nutrientes por três cultivares de alface cultivadas em condições do Semi-Árido. Horticultura Brasileira, v. 24, p. 190-194, 2006.

HICKMANN, Zachary A.; REID, Brian J. Earthworm assisted bioremediation of organic contaminants. Environment International, Vol. 34, pg. 1072 - 1081, 2008. Disponível em: <http://www.sciencedirect.com/science/article/pii/ S0160412008000342> Acesso em: 18 nov. 2016.

HOEHNE, Lucélia et al. Addition of Vermicompost to Heavy Metal-Contaminated Soil Increases the Ability of Black Oat (Avena strigosa Schreb) Plants to Remove Cd, $\mathrm{Cr}$, and $\mathrm{Pb}$. Springer International Publishing Switzerland, v. 12, p. 1-8, 2016.

JOHNSON, Daniel L. et al. T. Temporal changes in earthworm availability and extractability of polycyclic aromatic hydrocarbons in soil. Soil Biology \& Biochemistry, v. 34, p. 1363-1370, 2002.

KANALY, Robert A.; HARAYAMA, Shigeaki. Biodegradation of High-Molecular Weight Polycyclic Aromatic Hydrocarbons by Bacteria. Journal of Bacteriology, v. 182 , n. 8, p. 2059-2067, 2000.

KIEHL, E.J. Manual de compostagem maturação e qualidade do composto, Piracicaba, 1998.

LOUREIRO, Diego C. et al. Compostagem e vermicompostagem de resíduos domiciliares com esterco bovino para a produção de insumo orgânico. Pesquisa agropecuária Brasileira, Brasília, v. 42, n. 7, p.1043-1048, 2007. 
MARCONDES, A. C.; LAMMOGLIA, D. A. Biologia: ciência da vida. São Paulo: Atual, 1994.

MARTINI, Maira C. et al. Processo de vermicompostagem em lodo de curtume contendo cromo e após aplicação como biofertilizante em cultivo de cebolinha (Allium schoenoprasum). Anais do XXI seminário de iniciação científica da Unisc, v. 1, p. 212-212, 2015.

MARTINKOSKY, Luke et al. Earthworms (Eisenia fetida) demonstrate potential for use in soil bioremediation by increasing the degradation rates of heavy crude oil hydrocarbons. Science of the Total Environment, v. 580, p. 734-743, 2017.

PAGE, David S. et al. Pyrogenic Polycyclic Aromatic Hydrocarbons in sediments record past human activity. A case study in Prince William Sound, Alaska. Marine Pollution Bulletin, v.38, p.247-266, 1999.

PARRISH, Zakia D. et al. Accumulation of weathered polycyclic aromatic hydrocarbons (PAHs) by plant and earthworm species. Chemosphere, v. 64, p. 609-618, 2005.

SISINNO, Cristina L. S. et al. Hidrocarbonetos policíclicos aromáticos em resíduos sólidos industriais: uma avaliação preliminar do risco potencial de contaminação ambiental e humana em áreas de disposição de resíduos. Caderno de Saúde Pública, v. 19, n. 2, p. $671-676,2003$.

VALDERRAMA, Márcio et al. Fontes e doses de NPK em milho irrigado sob plantio direto. Pesq. Agropec. Trop., Goiânia, v. 41, n. 2, p. 254-263, 2011.

VERAS, Luciana R. V.; POVINELLI, Jurandyr. The vermicomposting of an industrial sludge combines with a compost of municipal solid refuse. Engenharia Sanitária e Ambiental, Rio de Janeiro, v. 9, n. 3, 2004. Disponível em: < http:/ / www.scielo.br/ scielo.php?pid=S1413-41522004000300008\&script=sci_arttext\&tlng=pt $>$ Acesso em: 20 dez. 2016.

WANGEN, Dalcimar R. B.; FREITAS, Isabel C. V. Compostagem doméstica: alternativa de aproveitamento de resíduos sólidos orgânicos. Revista Brasileira de Agroecologia, Uberlândia/MG, Brasil, v. 5(2), p. 81-88, 2010. Disponível em: < http:/ / aba-agroecologia.org.br/revistas/index.php/rbagroecologia/article/ view/7601/6696> Acesso em: 8. de nov. 2016.

YANG, Yan et al. Mobilization of soil organic matter by complexing agents and implications for polycyclic aromatic hydrocarbon desorption. Chemosphere, v. 43, p. 1013-1021, 2001. Disponível em: <http:/ / www.sciencedirect.com/science/article/ pii/S0045653500004987 > Acesso em: 18 nov. 2016.

YUNKER, Mark B. et al. PAHs in the Fraser River basin: a critical appraisal of PAH ratios as indicators of PAH source and composition. Organic Geochemistry, v. 33, p. 489-515, 2002. Disponível em: <http:/ / www.sciencedirect.com/science/article/pii/ S0146638002000025> Acesso em: 18 nov. 2016. 